\title{
Efficacy and safety of Monascus purpureus Went rice in subjects with hyperlipidemia
}

\author{
Cheng-Chieh Lin, Tsai-Chung $\mathrm{Li}^{1}$ and Ming-May Lai \\ Department of Family Medicine, China Medical University Hospital, Taichung 40447, Taiwan and ${ }^{1}$ Department of Institute of Chinese Medicine \& Public \\ Health, China Medical University, Taichung 40402, Taiwan
}

(Correspondence should be addressed to Ming-May Lai; Email: mmlai@ms26.hinet.net)

\begin{abstract}
Objective: The purpose of this study was to assess the lipid-lowering effect of Monascus purpureus Went rice on serum lipids in patients with hyperlipidemia, and to assess its safety by reporting adverse events and clinical laboratory measurements.

Design and methods: This was a randomized, double-blind, placebo-controlled study. In all, 79 patients (aged 23-65 years) with a mean baseline low-density lipoprotein cholesterol (LDL-C) level of $5.28 \mathrm{mmol} / \mathrm{l}(203.9 \mathrm{mg} / \mathrm{dl})$ received a twice daily dose of placebo or Monascus purpureus Went rice (600 mg) for 8 weeks.

Results: At week 8, Monascus purpureus Went rice therapy reduced LDL-C by $27.7 \%$, total cholesterol by $21.5 \%$, triglycerides by $15.8 \%$ and apolipoprotein B by $26.0 \%$. High-density lipoprotein cholesterol and apolipoprotein A-I levels were increased by 0.9 and 3.4\% respectively (not significant). No patient in the Monascus purpureus Went rice treatment group had an alanine aminotransferase (ALT), aspartate aminotransferase (AST) or creatine phosphokinase (CPK) measurement that was $\geq 3$ times the upper limit of normal at week 4 and week 8 .

Conclusion: Monascus purpureus Went rice significantly reduced LDL-C, total cholesterol, triglycerides and apolipoprotein B levels, and was well tolerated in patients with hyperlipidemia. However, this study only provides data from an 8-week trial and long-term safety and efficacy data are needed.
\end{abstract}

European Journal of Endocrinology 153 679-686

\section{Introduction}

Monascus purpureus rice (紅䅘 in Chinese), popularly called red yeast rice, is described as the fermented product of rice on which red yeast (Monascus purpureus) has been grown. This product has been used for centuries in China to make rice wine and to flavor foods. Traditional red yeast rice continues to be a dietary staple in many Asian countries, including China and Japan, with consumption ranging from 14 to $55 \mathrm{~g}$ /person per day (1). Recent studies have shown that Monascus purpureus rice contained 3-hydroxy-3-methylglutarylcoenzyme A reductase inhibitors (statins), large quantities of unsaturated fatty acids $(>125 \mathrm{mg} / \mathrm{g}$ Monascus purpureus rice preparation), beta-sitosterol, campesterol and stigmasterol $(2-4)$. These components are effective in reducing serum lipid (5). The lipid-lowering effects of Monascus purpureus rice have been shown in several animal models of hyperlipidemia to inhibit and prevent increases in total cholesterol, low-density lipoprotein cholesterol (LDL-C) and triglycerides (6). In this study, the efficacy and safety of Monascus purpureus Went rice were evaluated by measuring percentage changes of lipid profiles, observing any adverse effects and completing laboratory tests at regular intervals in subjects with hyperlipidemia.

\section{Subjects and methods}

\section{Participants}

The study's clinical phase began in December 2001 and was completed in January 2003. Subjects with hyperlipidemia in this study were recruited from the outpatient clinic at the China Medical University Hospital, Taichung, Taiwan or by advertising. Study participants were men and women aged 18-65 years with a body mass index of $<30 \mathrm{~kg} / \mathrm{m}^{2}$. Participants had to have a total cholesterol level $\geq 6.22 \mathrm{mmol} / \mathrm{l}(240 \mathrm{mg} / \mathrm{dl})$, an LDL-C level $\geq 4.14 \mathrm{mmol} / \mathrm{l}(160 \mathrm{mg} / \mathrm{dl})$ and a triglycerides level $\leq 4.52 \mathrm{mmol} / \mathrm{l}(400 \mathrm{mg} / \mathrm{dL})$ at two qualifying visits 4 weeks apart. Women who were pregnant or breastfeeding were excluded from the study, as were patients who met any of the following conditions: hypothyroidism, nephrotic syndrome or renal dysfunction (serum creatinine $>132.6 \mu \mathrm{mol} / \mathrm{l}(1.5 \mathrm{mg} / \mathrm{dl})$ ); diabetes mellitus; chronic gout; active liver disease or hepatic dysfunction (aspartate aminotransferase 
$($ AST) or alanine aminotransferase $($ ALT) $>2$ times the upper limit of normal (ULN)); creatine phosphokinase $(\mathrm{CPK})>3$ times the ULN; uncontrolled hypertension (systolic blood pressure $>160 \mathrm{mmHg}$ or diastolic blood pressure $>100 \mathrm{mmHg}$ ); cerebrovascular disease, cardiovascular surgery, myocardial infarction, coronary angioplasty, coronary artery bypass graft, severe or unstable angina, or major operations within 6 months prior to the study period; current or recent history of alcohol abuse; significant abnormalities that the investigator believed could compromise the patient's safety in participating in the study; participation in another clinical trial within the 30-day period before consideration for entry into this study; known hypersensitivity to lipid-modifying agents; and use of any drugs known to affect lipid levels, immunosuppressive agents, drugs associated with rhabdomyolysis in combination with statins (e.g. cyclosporine and erythromycin), or mibefradil dihydrochloride. Patients taking a lipid-lowering drug could be considered for screening after a 4-week washout period, with the exception of probucol - which had to have been discontinued for at least 6 months. The study complied with the Declaration of Helsinki. The institutional ethics review boards approved the protocol, and all participants gave their informed consent.

\section{Randomization and sample size determination}

A permuted-block randomization was employed to generate the random assignment of subjects by order of entry into two different treatment groups. Each group of subjects received either Monascus purpureus Went rice or placebo. In this study, a sample size of 79 patients was used for characterizing and comparing the efficacy as well as the safety of Monascus purpureus Went rice and placebo.

The sample size for this study was based on the primary efficacy outcome, the change from baseline to 8 weeks in mean LDL-C was compared between the two groups. The standard deviation (S.D.) of the mean LDLC level was $1 \mathrm{mmol} / \mathrm{l}$ (the S.D. of the mean for the treatment group and that of the placebo group were similar). We set the two-sided alpha (type I error) at 0.05 and the beta (type II error) at 0.10 (power of $90 \%$ ). According to these assumptions, a sample size of approximately 17 subjects in each group was needed to detect a difference of $1 \mathrm{mmol} / \mathrm{l}$ in mean LDL-C.

\section{Protocol}

After a minimum of 4 weeks on an American Heart Association Step I diet, 79 patients were instructed to continue the diet and were randomly assigned to 8 weeks of treatment with rice powder placebo or Monascus purpureus Went rice (Fig. 1). All patients received dietary instruction from a registered dietitian at every research visit and were contacted by telephone every week during the study. The study was double-blind. We reviewed participants every 4 weeks and blood samples were obtained after 12 -h overnight fasts. The laboratory staff responsible for analyses were blinded to treatment and received samples labeled with name codes and dates. The study protocol was approved by the Institutional Review Board of China Medical University Hospital and by the Department of Health, Taiwan.

\section{Monascus purpureus Went rice therapy}

For the treatment group, Monascus purpureus Went rice was pulverized and $600 \mathrm{mg}$ of this milled preparation

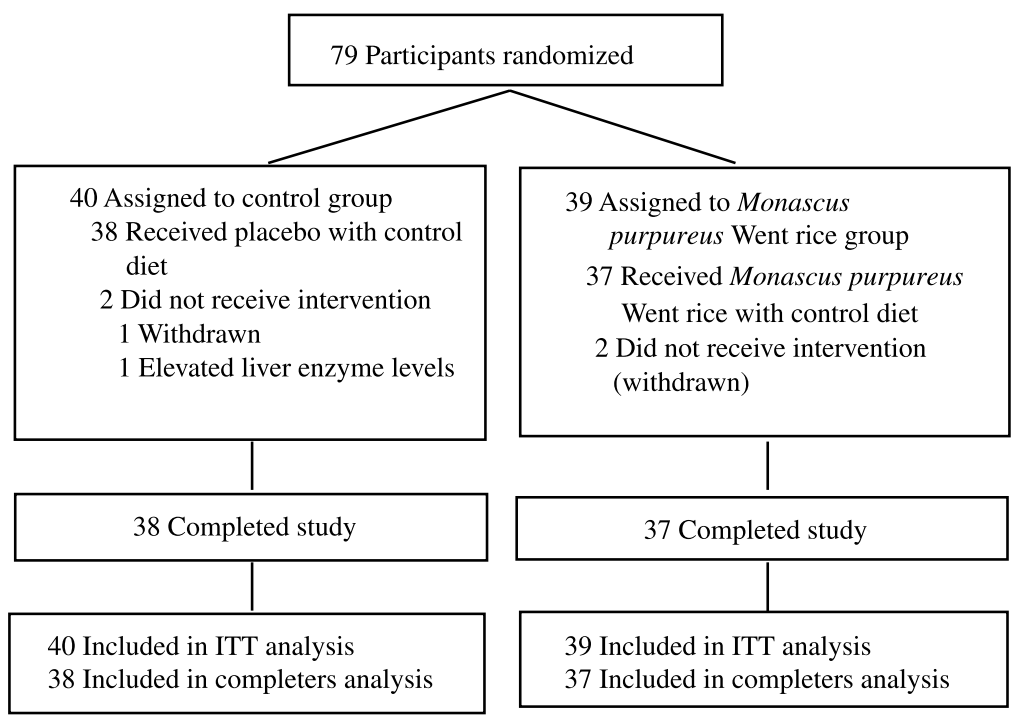

www.eje-online.org
Figure 1 Flow of patients through the trial. 
Table 1 Composition of Monascus purpureus Went rice.

\begin{tabular}{|c|c|}
\hline & Concentration \\
\hline Protein & $17.00 \%$ \\
\hline Starch & $68.00 \%$ \\
\hline Fat & $4.00 \%$ \\
\hline \multicolumn{2}{|l|}{ Of which: } \\
\hline Linoleic acid & $48.13 \%$ \\
\hline Oleic acid & $28.78 \%$ \\
\hline Palmitic acid & $18.61 \%$ \\
\hline Stearic acid & $4.49 \%$ \\
\hline Ergosterol & $0.30 \%$ \\
\hline Fiber & $2.00 \%$ \\
\hline Water & $<5.00 \%$ \\
\hline HMG-CoA reductase inhibitors (statins) & $1.16 \%$ \\
\hline Lovastatin & $0.95 \%$ \\
\hline Other statins & $0.21 \%$ \\
\hline r-Aminobutyric acid (GABA) & $2.55 \%$ \\
\hline \multicolumn{2}{|l|}{ Alkaloids } \\
\hline Water-soluble & $0.30 \%$ \\
\hline Lipid-soluble & $0.05 \%$ \\
\hline Glycosides & $0.06 \%$ \\
\hline Flavonoids & $0.05 \%$ \\
\hline Natural pigments & $0.01 \%$ \\
\hline Ethanol extracts & $\geq 12.00 \%$ \\
\hline Water extracts & $\geq 10.00 \%$ \\
\hline Citrinin & $<1.5$ p.p.m. ${ }^{\mathrm{a}}$ \\
\hline $\mathrm{Pb}$ & <20.0p.p.m. \\
\hline $\mathrm{Cd}$ & <0.6 p.p.m. \\
\hline $\mathrm{Hg}$ & <0.5 p.p.m. \\
\hline As & <5.0p.p.m. \\
\hline $\mathrm{Cu}$ & <70.0 p.p.m. \\
\hline
\end{tabular}

Data are based on unpublished analyses on file with $Y$ \& B Pharmaceuticals Co., Ltd, Taipei, Taiwan. HMG-CoA, 3-hydroxy-3-methylglutaryl coenzyme A. Percentage concentrations are percentage by weight.

${ }^{a}$ Mostly not detectable by HPLC.

encapsulated in each capsule under Good Manufacturing Practices conditions (Y \& B Pharmaceuticals Co., Ltd, Taipei, Taiwan). The composition of Monascus purpureus Went rice is shown in Table 1 . The placebo was made of grounded rice with food color mimicking the color and appearance of the active drug. Both Monascus purpureus Went rice and placebo capsules were dispensed by the hospital pharmacy in identical containers marked with the participant's name codes. Participants were asked to take one capsule $(600 \mathrm{mg}$ Monascus purpureus Went rice or placebo) twice daily, $30 \mathrm{~min}$ after breakfast and dinner, for the 56 days of the study, and to return the containers for capsule counts on each clinic visit.

\section{Analyses}

All samples from a given individual were labeled by code. Total cholesterol and triglycerides were determined by the enzymatic method using commercial kits (Beckman \& Coulter, Fullerton, CA, USA). Highdensity lipoprotein cholesterol (HDL-C) and LDL-C were measured by the direct method (7) using commercial kits (Beckman \& Coulter, LX 20 Pro, Japan). All the analyses were performed by Beckman \& Coutler, Tokyo autoanalyzer. The intra-assay coefficients of variation $(\mathrm{CV} \%)$ were $3.1,2.3,3.5$ and $3.6 \%$ for $\mathrm{LDL}-\mathrm{C}$, total cholesterol, triglycerides and HDL-C respectively. Serum apolipoprotein A-I and apolipoprotein B were measured by nephelometry (8) (intra-assay coefficient of variation, 2.2 and 1.9 respectively).

\section{Evaluation of efficacy}

The primary analysis of efficacy endpoints was based on the intent-to-treat population and completing participants. Baseline was defined as the measurements taken at randomization. The primary measure of efficacy was the percentage change in LDL-C level from baseline to week 8. Secondary measures of efficacy were percentage changes (from baseline to week 8) in total cholesterol, HDL-C, triglycerides, apolipoprotein A-I and apolipoprotein B.

\section{Safety analyses}

Safety was evaluated in all randomized patients who had taken at least one dose of study medication and provided any follow-up information. All adverse effects that occurred during the clinical trial were recorded. Their relation to the study drug (definitely, probably, possibly, unlikely, definitely not) and their intensity (mild, moderate, severe) were assessed by the investigator. Because statins are present in Monascus purpureus Went rice, ALT, AST and CPK were measured. In addition, physical examinations and clinical laboratory determinations were performed at screening, randomization, week 4 and study termination.

\section{Statistical methods}

Descriptive statistics such as a number of observations, means, standard deviations and percentages were used to summarize the baseline variables. All available tests were two sided and were evaluated at the 0.05 level of significance. For subjects' demographic information, the comparability between two groups was examined using an unpaired $t$-test for continuous variables, and Fisher's exact test and Mantel-Haenszel test for categorical variables. Blood lipids, safety parameters, vital signs and laboratory examinations were analyzed based on change from baseline; they were analyzed by unpaired $t$-test for between-group variation, and by paired $t$-test for within-group variation. Fisher's exact test was used to compare the number of subjects with adverse effects between groups.

\section{Role of the funding source}

The sponsors of the study had no role in study design, data collection, data analysis, data interpretation, or writing of the report. 
Table 2 Patient characteristics at baseline by treatment group.

\begin{tabular}{llcl}
\hline & $\begin{array}{c}\text { Placebo } \\
(n=40)\end{array}$ & $\begin{array}{c}\text { Monascus } \\
\text { purpureus } \\
\text { Went rice }(n=39)\end{array}$ & $\boldsymbol{P}$ value \\
\hline Age (years) & $46.5 \pm 9.5$ & $46.3 \pm 10.1$ & $0.922^{\mathrm{a}}$ \\
Sex, male & $22(55 \%)$ & $23(59 \%)$ & $0.821^{\mathrm{b}}$ \\
BMl (kg/m $\left.{ }^{2}\right)$ & $23.4 \pm 2.7$ & $24.3 \pm 3.3$ & $0.161^{\mathrm{a}}$ \\
Smoking history & & & $0.681^{\mathrm{c}}$ \\
$\quad$ Never smoked & $34(85 \%)$ & $32(82 \%)$ & \\
Current smoker & $4(10 \%)$ & $6(15 \%)$ & $0.193^{\mathrm{c}}$ \\
Alcohol history & $33(83 \%)$ & $36(92 \%)$ & \\
$\quad$ Never & $0(0 \%)$ & $0(0 \%)$ & \\
Abusive & &
\end{tabular}

Data are means \pm S.D.or number with percentage in brackets. BMI, body mass index.

anpaired $t$ test.

${ }^{b}$ Fisher's exact test.

${ }^{c}$ Mantel-Haenszel test.

\section{Results}

\section{Patient characteristics at baseline}

The characteristics of subjects who entered the study are summarized in Table 2. The demographics and baseline characteristics of subjects in the two groups were similar. The percentage of males and females was about equal in both groups. The age of subjects in both groups was about 46 years with a range of $23-65$ years. Over $80 \%$ of subjects in both groups had never smoked. A high percentage of subjects in both groups had never had alcohol. Both groups had comparable body mass indices (BMI).

At baseline, there were no significant differences between groups for the efficacy parameters (LDL-C, total cholesterol, HDL-C, triglycerides, apolipoprotein A-I and apolipoprotein B). All these data affirmed that the distribution of subjects between the two groups was well balanced (Table 3).

\section{Exposure}

Of the 79 patients randomized to treatment, 39 received Monascus purpureus Went rice and 40 placebo. Four participants who were randomized did not start the study (Monascus purpureus Went rice, 2 patients (5.1\%); placebo, 2 patients $(5.0 \%))$. Compliance with study therapy (defined as $\geq 80 \%$ of pills taken) was $81.6 \%$ for placebo and $89.2 \%$ for Monascus purpureus Went rice.

\section{Lipid and lipoprotein response}

Efficacy evaluation was carried out on completing participants, in which 75 subjects were included. LDL-C levels, the primary efficacy endpoint, were comparable between the two groups at baseline (Table 3). The Monascus purpureus Went rice reduced LDL-C levels by $27.7 \%$ but placebo caused only a $1.5 \%$ decrease at week 8. At baseline, the two groups showed comparable total cholesterol, triglycerides and apolipoprotein B levels $(P>0.05)$. The 8-week treatment with Monascus purpureus Went rice significantly reduced total cholesterol levels by $21.5 \%$, triglycerides by $15.8 \%$ and apolipoprotein B by $26 \%$. Worthy of special mention is that Monascus purpureus Went rice resulted in reductions in LDL-C level by $30.6 \%$, total cholesterol level by $23.7 \%$, triglycerides level by $13.4 \%$ and apolipoprotein B level by $28.9 \%$ that were observed as early as 4 weeks after its administration (Table 3). In contrast, the placebo treatment resulted in almost no reduction of total cholesterol $(-0.4 \%)$ and triglycerides $(+1 \%)$ at week 4 and week 8 . A $3.9 \%$ reduction of apolipoprotein B levels was observed after the placebo treatment at week 8. The capacity of Monascus purpureus Went rice to change HDL-C and apolipoprotein A-I levels was limited. The difference in the percentage change of HDL-C and apolipoprotein A-I was comparable between the two groups $(P>0.05)$.

\section{Safety analyses}

A safety evaluation was performed based on the "safety population', which included a total of 75 subjects ( $n=37$ in the Monascus purpureus Went rice group and $n=38$ in the placebo group) who were randomized and had taken at least one dose of the study medication, with follow-up information after randomization. We recorded any complaints mentioned, however trivial. Therefore, up to $65 \%$ of the total safety population $(n=49)$ reported one or more adverse events and $8 \%$ of the total safety population $(n=6)$ had one or more drug-related adverse events. Nevertheless, the incidence of 'one or more adverse events', 'drug-related adverse events' and 'serious adverse events' between the two groups were comparable $(P>0.05)$ (Table 4). Monascus purpureus Went rice treatment produced a slight increase in ALT (2.3 U/l) and AST (0.8 U/l), but no patient had an ALT or AST measurement $\geq 3$ times the ULN at week 4. At week 8, Monascus purpureus Went rice had the same safety profile. Baseline serum CPK was similar in both groups and was not significantly different after 8 weeks of the treatment. In the Monascus purpureus Went rice group, mean serum CPK at baseline was $116.4 \mathrm{U} / \mathrm{l}(\mathrm{S} . \mathrm{D} .=66.0)$ and mean serum CPK at week 8 was $129.6 \mathrm{U} / \mathrm{l}($ S.D. $=42.3)$. In addition, there was no patient with myopathy (defined as a CPK level $\geq 10$ times the ULN with muscle symptoms) or CPK values $\geq 3$ times the ULN at weeks 4 and 8. In particular, no cases of rhabdomyolysis or anaphylaxis were observed. In addition, Monascus purpureus Went rice did not alter other safety parameters including vital signs, results of physical examination, hematology, serum chemistry, urine analysis and electrocardiogram. 
Table 3 Change from baseline in serum lipid variables, by week and treatment group (completer population).

\begin{tabular}{|c|c|c|c|c|c|}
\hline \multirow[b]{2}{*}{ Lipid parameter } & \multirow[b]{2}{*}{ Week } & \multicolumn{2}{|c|}{ Placebo $(n=38)$} & \multicolumn{2}{|c|}{ Monascus purpureus Went rice $(n=37)$} \\
\hline & & Level & Percentage change & Level & Percentage change \\
\hline \multirow[t]{3}{*}{ LDL-C (mmol/l) $)^{\mathrm{a}}$} & 0 & $5.34 \pm 1.15$ & & $5.20 \pm 0.86$ & \\
\hline & 4 & $5.27 \pm 1.14$ & $-0.5 \pm 14.1$ & $3.61 \pm 0.83^{\star}, \ddagger$ & $-30.6 \pm 10.1 \ddagger$ \\
\hline & 8 & $5.19 \pm 1.01$ & $-1.5 \pm 16.0$ & $3.76 \pm 0.85^{\star}, \ddagger$ & $-27.7 \pm 12.2 \ddagger$ \\
\hline \multirow[t]{3}{*}{$\mathrm{TC} \mathrm{mmol} / \mathrm{l}^{\mathrm{a}}$} & 0 & $7.41 \pm 1.12$ & & $7.27 \pm 0.83$ & \\
\hline & 4 & $7.34 \pm 1.15$ & $-0.5 \pm 10.9$ & $5.54 \pm 0.76^{\star}, \ddagger$ & $-23.7 \pm 7.2 \ddagger$ \\
\hline & 8 & $7.37 \pm 1.19$ & $-0.4 \pm 9.5$ & $5.68 \pm 0.79^{*}, \ddagger$ & $-21.5 \pm 9.4 \ddagger$ \\
\hline \multirow{3}{*}{$\mathrm{HDL}-\mathrm{C} \mathrm{mmol} / \mathrm{l}^{\mathrm{a}}$} & 0 & $1.32 \pm 0.28$ & & $1.31 \pm 0.39$ & \\
\hline & 4 & $1.32 \pm 0.30$ & $0.5 \pm 11.5$ & $1.30 \pm 0.35$ & $0.4 \pm 8.8$ \\
\hline & 8 & $1.33 \pm 0.31$ & $1.0 \pm 10.2$ & $1.30 \pm 0.32$ & $0.9 \pm 10.6$ \\
\hline \multirow{3}{*}{$\mathrm{TG} \mathrm{mmol} / \mathrm{l}^{\mathrm{b}}$} & 0 & $1.38 \pm 0.66$ & & $1.46 \pm 0.72$ & \\
\hline & 4 & $1.38 \pm 0.71$ & $5.3 \pm 32.3$ & $1.26 \pm 0.82 \dagger \S$ & $-13.4 \pm 33.5 \S$ \\
\hline & 8 & $1.31 \pm 0.63$ & $1.0 \pm 34.4$ & $1.22 \pm 0.72 \dagger \S$ & $-15.8 \pm 25.1 \S$ \\
\hline \multirow[t]{3}{*}{ Apo A-I $(g / l)^{c}$} & 0 & $1.34 \pm 0.25$ & & $1.34 \pm 0.22$ & \\
\hline & 4 & $1.32 \pm 0.23$ & $0.0 \pm 16.3$ & $1.34 \pm 0.21$ & $1.0 \pm 12.2$ \\
\hline & 8 & $1.35 \pm 0.20$ & $2.3 \pm 12.8$ & $1.37 \pm 0.21$ & $3.4 \pm 14.0$ \\
\hline \multirow[t]{3}{*}{ Apo B $(g / l)^{c}$} & 0 & $1.57 \pm 0.30$ & & $1.54 \pm 0.27$ & \\
\hline & 4 & $1.51 \pm 0.30$ & $-3.2 \pm 12.7$ & $1.10 \pm 0.25^{\star}, \ddagger$ & $-28.9 \pm 8.9 \ddagger$ \\
\hline & 8 & $1.50 \pm 0.33$ & $-3.9 \pm 12.2$ & $1.14 \pm 0.27^{*}, \ddagger$ & $-26.0 \pm 14.3 \ddagger$ \\
\hline
\end{tabular}

Data are means \pm S.D.TC, total cholestrol; TG, triglycerides; Apo A-I, apolipoprotein A-I; Apo B, apolipoprotein B.

${ }^{a}$ To convert total cholesterol, HDL-C and LDL-C to $\mathrm{mg} / \mathrm{dL}$, divide values by 0.0259 .

${ }^{\mathrm{b}}$ To convert triglyceridess to $\mathrm{mg} / \mathrm{dL}$, divide values by 0.0113 .

${ }^{\mathrm{c}}$ To convert Apo A-I and Apo B to $\mathrm{mg} / \mathrm{dL}$, divide values by 0.01

* Significantly different from baseline, $P<0.001$.

† Significantly different from baseline, $P<0.05$.

$\ddagger$ Significantly different from control group at the same week, $P<0.001$.

$\S$ Significantly different from control group at the same week, $P<0.05$.

Table 4 Number and percentage of patients with adverse events (AEs).

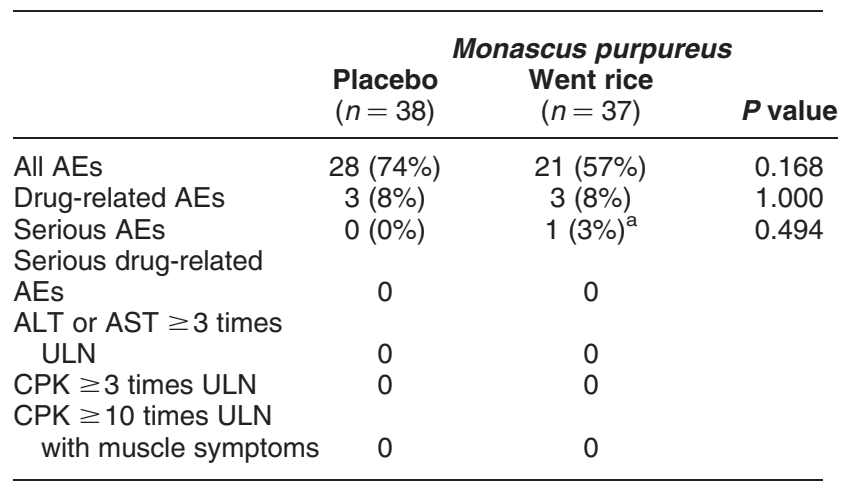

${ }^{\mathrm{a}}$ Breast cancer: unrelated to the study drug.

During the trial, one serious adverse event (breast carcinoma) occurred in the Monascus purpureus Went rice-treated group. The 63-year-old female was diagnosed with breast cancer after a 4-week administration of Monascus purpureus Went rice. However, the incident was not related to Monascus purpureus Went rice.

\section{Intention-to-treat analysis}

This study was also analyzed on the basis of intention to treat, including the four individuals with baseline values who dropped out or were withdrawn. The differences in blood lipid levels were significantly different between the treatment groups, as was observed when these participants were not included in the analysis (Table 5). Furthermore, the mean reduction in LDL-C level across treatments was still significant at 26.3\% $(13.4 \%)(P<0.001)$ for the Monascus purpureus Went rice-treated group when it was assumed that the four additional participants showed no change in response to the treatment.

\section{Discussion}

Coronary artery disease (CAD) is a leading cause of death in the developed world today. It is well established that increased total cholesterol, LDL-C and triglycerides concentrations, as well as decreased HDL-C concentrations, are strong independent predictors of CAD (9). The statins have repeatedly been shown to reduce mean serum LDL-C concentrations by $28-$ $35 \%$ in long-term trials $(10-12)$, with corresponding reductions in cardiovascular death of $23-32 \%$ in both primary and secondary prevention trials (11, 12). A previous study showed that red yeast rice resulted in significant reductions in LDL-C $(1.00 \mathrm{mmol} / \mathrm{l})$, total cholesterol $(1.09 \mathrm{mmol} / \mathrm{l})$ and triglycerides $(0.17 \mathrm{mmol} / \mathrm{l})$ levels (2). In this study, Monascus purpureus Went rice resulted in significant reductions in LDL-C $(1.59 \mathrm{mmol} / \mathrm{l}(30.6 \%))$, total cholesterol $(1.73 \mathrm{mmol} / \mathrm{l}(23.7 \%))$ and triglycerides $(0.21 \mathrm{mmol} / \mathrm{l}(13.4 \%))$ levels from baseline to week 4. These reductions were maintained at 8 weeks. 
Table 5 Change from baseline in serum lipid variables, by week and treatment group (intent-to-treat population).

\begin{tabular}{|c|c|c|c|c|c|}
\hline \multirow[b]{2}{*}{ Lipid parameter } & \multirow[b]{2}{*}{ Week } & \multicolumn{2}{|c|}{ Placebo $(n=40)$} & \multicolumn{2}{|c|}{ Monascus purpureus Went rice $(n=39)$} \\
\hline & & Level & Percentage change & Level & Percentage change \\
\hline \multirow[t]{3}{*}{ LDL-C $(\mathrm{mmol} / \mathrm{l})^{\mathrm{a}}$} & 0 & $5.35 \pm 1.12$ & & $5.20 \pm 0.84$ & \\
\hline & 4 & $5.01 \pm 1.61$ & $-0.5 \pm 13.7$ & $3.43 \pm 1.14^{\star}, \ddagger$ & $-29.1 \pm 12.0 \ddagger$ \\
\hline & 8 & $5.22 \pm 0.99$ & $-1.4 \pm 15.6$ & $3.83 \pm 0.89^{\star}, \mp$ & $-26.3 \pm 13.4 \ddagger$ \\
\hline \multirow{3}{*}{$\mathrm{TC}(\mathrm{mmol} / \mathrm{l})^{\mathrm{a}}$} & 0 & $7.40 \pm 10.9$ & & $7.28 \pm 0.84$ & \\
\hline & 4 & $6.97 \pm 1.97$ & $-0.5 \pm 10.7$ & $5.26 \pm 1.44^{\star}, \ddagger$ & $-22.5 \pm 8.8 \ddagger$ \\
\hline & 8 & $7.36 \pm 1.16$ & $-0.4 \pm 9.3$ & $5.78 \pm 0.89^{\star}, \ddagger$ & $-20.4 \pm 10.3 \ddagger$ \\
\hline \multirow[t]{3}{*}{$\mathrm{HDL}-\mathrm{C}(\mathrm{mmol} / \mathrm{l})^{\mathrm{a}}$} & 0 & $1.32 \pm 0.28$ & & $1.32 \pm 0.42$ & \\
\hline & 4 & $1.25 \pm 0.41$ & $0.5 \pm 11.2$ & $1.23 \pm 0.45$ & $0.4 \pm 8.6$ \\
\hline & 8 & $1.33 \pm 0.30$ & $1.0 \pm 10.0$ & $1.32 \pm 0.36$ & $0.9 \pm 10.4$ \\
\hline \multirow[t]{3}{*}{$\mathrm{TG}(\mathrm{mmol} / \mathrm{l})^{\mathrm{b}}$} & 0 & $1.34 \pm 0.67$ & & $1.46 \pm 0.72$ & \\
\hline & 4 & $1.31 \pm 0.75$ & $5.0 \pm 31.5$ & $1.19 \pm 0.84 \dagger, \S$ & $-12.7 \pm 32.8 \S$ \\
\hline & 8 & $1.27 \pm 0.63$ & $0.9 \pm 33.5$ & $1.22 \pm 0.72 \dagger, \S$ & $-15.0 \pm 24.7 \S$ \\
\hline \multirow[t]{3}{*}{ Apo A-I $(g / /)^{c}$} & 0 & $1.33 \pm 0.25$ & & $1.37 \pm 0.29$ & \\
\hline & 4 & $1.26 \pm 0.37$ & $0.0 \pm 15.9$ & $1.27 \pm 0.36$ & $1.0 \pm 11.9$ \\
\hline & 8 & $1.34 \pm 0.20$ & $2.2 \pm 12.4$ & $1.40 \pm 0.28$ & $3.2 \pm 13.6$ \\
\hline \multirow[t]{3}{*}{ Apo B $(g / /)^{c}$} & 0 & $1.56 \pm 0.30$ & & $1.55 \pm 0.26$ & \\
\hline & 4 & $1.43 \pm 0.44$ & $-3.1 \pm 12.4$ & $1.05 \pm 0.35^{\star}, \ddagger$ & $-27.4 \pm 10.8 \ddagger$ \\
\hline & 8 & $1.50 \pm 0.32$ & $-3.7 \pm 11.9$ & $1.16 \pm 0.28^{*}$ & $-24.7 \pm 15.1 \neq$ \\
\hline
\end{tabular}

Data are means \pm S.D. Abbreviations and symbols are as in Table 3.

The results of this study again confirm that Monascus purpureus Went rice has positive effects on plasma lipids.

It is noteworthy that Monascus purpureus Went rice reduced apolipoprotein B levels by $26.0 \%$ in this study. Each of the atherogenic particles - namely, very low density lipoprotein, intermediate-density lipoprotein, LDL and lipoprotein(a) - contain one molecule of apolipoprotein B. Thus, the serum concentration of apolipoprotein $B$ reflects the total number of these particles. A systematic review showed the apolipoprotein B concentration to be a better estimate of the risk of vascular events than the LDL-C level (13). This is supported by the fact that apolipoprotein $\mathrm{B}$ has been accepted as an alternative to the cholesterol indices in the new Canadian Lipid Working Group on hypercholesterolemia and other dyslipidemias (14) and in the new Canadian Diabetes Association Guidelines (15).

A specialist commented that Monascus purpureus Went rice contains statins and yields similar hypolipidemic effects to statins (16), therefore the other active components may only play a minor role in the action of Monascus purpureus Went rice. One study (17) reported mean LDL-C reductions to be 20, 26, 19 and $24 \%$ for fluvastatin $(80 \mathrm{mg})$, lovastatin $(80 \mathrm{mg})$, pravastatin $(40 \mathrm{mg})$ and simvastatin $(20 \mathrm{mg})$ respectively; mean apolipoprotein B levels were reduced by 16, 19, 16 and $20 \%$ respectively. In this study, $1200 \mathrm{mg}$ of Monascus purpureus Went rice contains a total of $13.9 \mathrm{mg}$ statins (contains $11.4 \mathrm{mg}$ lovastatin) but reduced LDL-C by $27.7 \%$ and apolipoprotein $\mathrm{B}$ by $26.0 \%$. Hence, we infer that the hypolipidemic effect of Monascus purpureus Went rice is unlikely to be due solely to statins, but rather to result from other substances in the Monascus purpureus Went rice. Monascus purpureus Went rice also contains phytosterols, mainly beta-sitosterol with campesterol and stigmasterol. Plant sterols have been shown to decrease total cholesterol and LDL-C concentrations in several population groups $(18-21)$.

In this study, all patients received dietary consultation but there was no record of diets of the participants. We compared BMI in the two treatment groups at baseline, at 4 weeks and at 8 weeks. There were no significant differences in BMI within or between study groups. Therefore, we infer that neither dietary fat intake or exercise had an impact on lipid profile in the study period.

Asymptomatic elevations of transaminases ( $>3$ times the ULN) have been observed with all the statins, are relatively common $(0.1-2.0 \%)$ and are dose related (22). It is interesting to note that no patient in the Monascus purpureus Went rice treatment group had an ALT or AST measurement $\geq 3$ times the ULN at week 4 or week 8 . Statin therapy is also known to cause increases in CPK activity, mostly during the initial stages of treatment and upward dose titration. Nevertheless, no trials have examined the effect of red yeast rice on CPK so far. In this study, no cases of CPK measurement $\geq 3$ times the ULN or rhabdomyolysis were reported. Possible Monascus purpureus Went rice-related adverse events were one abnormal liver function test (ALT, $57 \mathrm{U} / \mathrm{l}$; ULN 40 U/l), one CPK increase (151 U/l; ULN, $140 \mathrm{U} / \mathrm{l})$, and one lactate dehydrogenase increase (208 U/l; ULN, 192 U/l). All these events were mild in severity and required no treatment. On the other hand, mild leukopenia $(n=1)$, diarrhea $(n=1)$ and nausea $(n=1)$ were found to be possibly drug-related adverse events in the placebo treated group. In general, Monascus purpureus Went rice was well tolerated and no 
one discontinued the study due to adverse effects caused by the study drug. Extensive animal studies of red yeast rice extracts have been conducted. In an acute toxicity study in mice, there were no toxic effects noted when a single dose of the extract was administered at 533 times the typical human dose (23).

More recently, citrinin has also been isolated from Monascus ruber and Monascus purpureus, industrial species used to produce red pigments (24). Citrinin acts as a nephrotoxin in all animal species tested, but its acute toxicity varies in different species (25). The $50 \%$ lethal dose for ducks is $57 \mathrm{mg} / \mathrm{kg}$; for chickens it is $95 \mathrm{mg} / \mathrm{kg}$; and for rabbits it is $134 \mathrm{mg} / \mathrm{kg}$ (26). In addition, wheat, oats, rye, corn, barley and rice have all been reported to contain citrinin (27). Although citrinin is regularly associated with human foods, its significance for human health is unknown. In the present study, citrinin was not detected in Monascus purpureus Went rice.

Worthy of mention is the fact that Monascus purpureus Went is a specific strain of red yeast and a different strain of Monascus could result in different efficacy and safety profiles. Accordingly, red yeast rice material produced in the traditional way has yielded different amounts of active compounds compared with the Monascus purpureus Went rice extract. In other words, the home-processed red yeast rice may not exhibit the same hypolipidemic effect as the Monascus purpureus Went rice extract (16).

In summary, the significant effect of Monascus purpureus Went rice in reducing LDL-C, total cholesterol, triglycerides and apolipoprotein B levels was found as early as week 4 and was consistent until week 8. Moreover, no patient in the Monascus purpureus Went rice treatment group had an ALT, AST or CPK measurement $\geq 3$ times the ULN at week 4 and week 8 . However, this study only provides 8 weeks of data and further studies on the long-term safety and efficacy of Monascus purpureus Went rice in a larger population are needed.

\section{Acknowledgements}

Y \& B Pharmaceuticals Co., Ltd, Taipei, Taiwan supplied the rice extract.

\section{References}

1 Mei F. Red yeast flavored duck. In Fang Mei's Illustrated Cookbook of Regional Chinese Cuisine, pp 177-188. Guangxi, Peoples' Republic of China: Guangxi National Press, 1990.

2 Heber D, Yip I, Ashley JM, Elashoff DA, Elashoff RM \& Go VL. Cholesterol-lowering effects of a proprietary Chinese red-yeastrice dietary supplement. American Journal of Clinical Nutrition $199969231-236$.

3 Ma J, Li Y, Ye Q, Li J, Hua Y, Ju D, Zhang D, Cooper R \& Chang M. Constituents of red yeast rice, a traditional Chinese food and medicine. Journal of Agriculture and Food Chemistry 200048 5220-5225.

4 Wang J, Lu Z, Chi J, Wang W, Su M, Kou W, Yu P, Y'u L, Chen L, Zhu J-S \& Chang J. Multicenter clinical trial of the serum lipid- lowering effects of a monascus purpureus (red yeast) rice preparation from traditional Chinese medicine. Current Therapeutic Research 199758 964-978.

5 Goldstein MR. Effects of dietary phytosterols on cholesterol metabolism and atherosclerosis. American Journal of Medicine $200010972-73$.

6 Wei W, Li C, Wang Y, Su H, Zhu J \& Kritchevsky D. Hypolipidemic and anti-atherogenic effects of long-term Cholestin (Monascus purpureus-fermented rice, red yeast rice) in cholesterol fed rabbits. Journal of Nutritional Biochemistry 200314 314-318.

7 Sugiuchi H, Uji Y, Okabe H, Irie T, Uekama K, Kayahara N \& Miyauchi K. Direct measurement of high-density lipoprotein cholesterol in serum with polyethylene glycol-modified enzymes and sulfated alpha-cyclodextrin. Clinical Chemistry 199541 717-723.

8 Fink PC, Romer M, Haeckel R, Fateh-Moghadam A, Delanghe J, Gressner AM \& Dubs RW. Measurement of proteins with the Behring Nephelometer. A multicentre evaluation. Journal of Clinical Chemistry and Clinical Biochemistry 198927 261-276.

9 NCEP Expert Panel, Summary of the third report of the National Cholesterol Education Program (NCEP) Expert Panel on Detection, Evaluation, and Treatment of High Blood Cholesterol in Adults (Adult Treatment Panel III). Journal of the American Medical Association $20012852486-2497$.

10 Scandinavian Simvastatin Survival Study Group, Randomized trial of cholesterol lowering in 4444 patients with coronary heart disease: the Scandinavian Simvastatin Survival Study (4S). Lancet 1994344 1383-1389.

11 Downs JR, Clearfield M, Weis S, Whitney E, Shapiro DR, Beere PA, Langendorfer A, Stein EA, Kruyer W \& Gotto AM Jr. Primary prevention of acute coronary events with lovastatin in men and women with average cholesterol levels: results of AFCAPS/TexCAPS: Air Force/Texas Coronary Atherosclerosis Prevention Study. Journal of the American Medical Association 1998279 1615-1622.

12 Heart Protection Study Collaborative Group, MRC/BHF Heart Protection Study of cholesterol lowering with simvastatin in 20,536 high-risk individuals: a randomised placebo-controlled trial. Lancet $20023607-22$.

13 Sniderman AD, Furberg CD, Keech A, Roeters van Lennep JE, Frohlich J, Jungner I \& Walldius G. Apolipoproteins versus lipids as indices of coronary risk and as targets for statin treatment. Lancet $2003361777-780$.

14 Genest J, Frohlich J, Fodor G \& McPherson R. Working group on hypercholesterolemia and other dyslipidemias. Recommendations for the management of dyslipidemia and the prevention of cardiovascular disease: summary of the 2003 update. Canadian Medical Association Journal 2003162 1441-1447.

15 Leiter LA, Mahon J, Ooi TC, Grover S, Kraw M, Lewis G, Sigal RJ \& Steiner G. Macrovascular complications, dyslipidemia and hypertension. Canadian Journal of Diabetes 200327 S58-S65.

16 Havel RJ. Dietary supplement or drug? The case of cholestin. American Journal of Clinical Nutrition 199969 175-176.

17 Schaefer EJ, McNamara JR, Tayler T, Daly JA, Gleason JL, Seman LJ, Ferrari A \& Rubenstein JJ. Comparisons of effects of statins (atorvastatin, fluvastatin, lovastatin, pravastatin, and simvastatin) on fasting and postprandial lipoproteins in patients with coronary heart disease versus control subjects. American Journal of Cardiology 200493 31-39.

18 Bourque C, St-Onge MP, Papamandjaris AA, Cohn JS \& Jones PJ. Consumption of an oil composed of medium chain triacyglycerols, phytosterols, and N-3 fatty acids improves cardiovascular risk profile in overweight women. Metabolism 200352 771-777.

19 Hendriks HF, Brink EJ, Meijer GW, Princen HM \& Ntanios FY. Safety of long-term consumption of plant sterol esters-enriched spread. European Journal of Clinical Nutrition $20035 \mathbf{5 7} 681-692$.

20 Ketomaki AM, Gylling H, Antikainen M, Siimes MA \& Miettinen TA. Red cell and plasma plant sterols are related during consumption of plant stanol and sterol ester spreads in children with hypercholesterolemia. Journal of Pediatrics 2003 $142524-531$. 
21 Hendriks HF, Weststrate JA, van Vliet T \& Meijer GW. Spreads enriched with three different levels of vegetable oil sterols and the degree of cholesterol lowering in normocholesterolaemic and mildly hypercholesterolaemic subjects. European Journal of Clinical Nutrition 199953 319-327.

22 Tolman KG. Defining patient risks from expanded preventive therapies. American Journal of Cardiology 200085 15E-19E.

$23 \mathrm{Li} \mathrm{CL}$, Li YF \& Hou ZL. Xuezhikang toxicity study. Bulletin of the Chinese Pharmacological Society 1995123.

24 Blanc PJ, Loret MO \& Goma G. Production of citrinin by various species of Monascus [letter]. Biotechnology 199517 291-294.

25 Carlton WW \& Tuite J. Metabolites of P. viridicatum toxicology. In Mycotoxins in Human and Animal Health, pp 525-555. Eds JV
Rodricks, CW Hesseltine \& MA Mehlmann. Park Forest South, Illinois, USA: Pathotox, 1977.

26 Hanika C \& Carlton WW. Toxicology and pathology of citrinin. In Biodeterioration Research 4, pp 41-63. Eds GC Llewellyn, WV Dashek \& CE O'Rear. New York: Plenum Press, 1994.

27 Abramson D, Usleber E \& Martlbauer E. Immunochemical method for citrinin. In Mycotoxin Protocols, pp 195-204. Eds MW Trucksess \& AE Pohland. Totowa, New Jersey: Humana Press, 2001.

Received 16 May 2005

Accepted 27 July 2005 